\title{
La crisis hídrica, señal para la
} 23 de enero de 2022

\section{transformación}

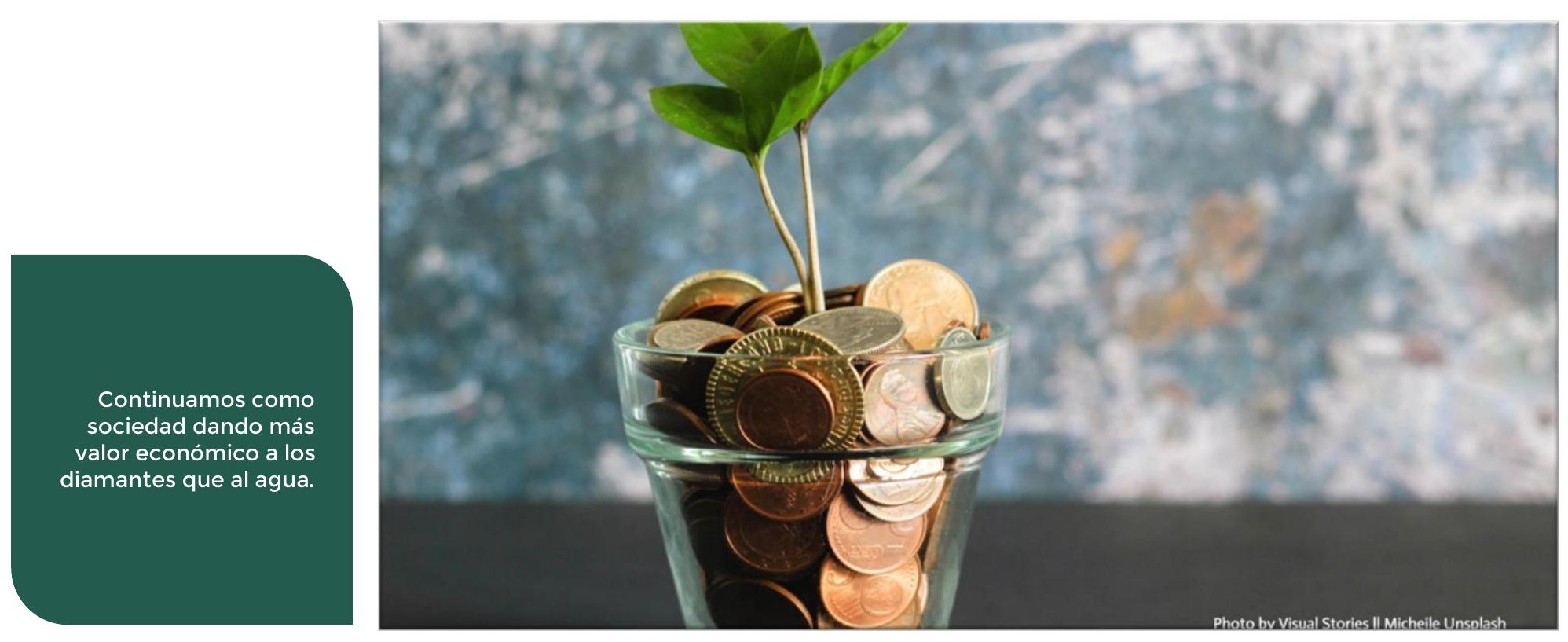

En el 2027, las múltiples crisis que enfrentamos como humanidad y su interrelación con el bienestar de las personas quedaron expuestas.

A finales del año, la pandemia de COVID-19 todavía se dejó sentir con fuerza a través de la variante ómicron, que dio inicio a una cuarta ola de contagios, aunque con menos poder letal que las anteriores. Por si esta crisis de salud pública mundial fuera poco, el planeta nos manda otras señales inequívocas que nos obligan como humanidad a reorientar nuestras prioridades globales y nacionales.

Una señal evidente es la crisis hídrica que enfrentan todos los países del mundo y que afecta a todos, inclusive a aquellos que tienen las mayores reservas de agua. Por ejemplo, Brasil, nación con la mayor disponibilidad de agua dulce en el mundo, enfrenta en estos momentos una de las sequías más severas en su historia reciente. Desde el punto de vista hídrico, Brasil es una superpotencia. Tan solo dos tercios del volumen de agua de uno de sus ríos, el Amazonas, tiene la capacidad de satisfacer la demanda mundial de agua. Esta disponibilidad real de agua convierte a esta nación en un productor de alimentos importantísimo, pues produce una tercera parte de toda la caña de azúcar consumida en el mundo y casi el $15 \%$ de carne roja.

Entre marzo y mayo de 2021, la región centro-sur de Brasil experimentó una sequía que dejó a una región de $267 \mathrm{~km} 2$ bajo condiciones de escasez hídrica en ríos, lagos y acuíferos (comparada con condiciones 
promedio de los últimos 20 años). Esto resultó en que el almacenamiento de muchas de las grandes presas de ese país no alcanzara ni el 20 \% de su capacidad, generando impactos negativos sobre la producción de alimentos y energía. A su vez, esto derivó en cambios en los precios de algunos productos, como el café, que desde julio registró un incremento del 30 \% (Brasil produce y exporta una tercera parte del café consumido en todo el mundo). De igual manera, entre los meses de junio de 2020 y mayo de 2021, la soya también registró un incremento del 67 \% y los precios de la electricidad subieron hasta en un $130 \%$. Por si esto fuera poco, muchas ciudades del sur tuvieron que racionar el agua a sus habitantes. Naturalmente, existe un impacto negativo importante sobre la economía de las personas y en particular de aquellas que menos tienen.

Así es como la crisis hídrica global se manifiesta de manera local en una nación con vastas reservas de agua (20 \% del escurrimiento terrestre global hacia los océanos se origina en Brasil) (Geritana, 2016). Por esta razón, sostenemos que el agua es el elemento clave para generar bienestar y crecimiento económico no solo en esta, sino en todas las naciones del planeta.

Brasil ocupa el segundo lugar global en capacidad de generación hidroeléctrica instalada, con 107.4 GW, y sus embalses producen $65 \%$ de toda la energía que consumen. De esta energía hidroeléctrica $40 \%$ se genera en el río Paraná, donde los caudales han caído a sus niveles más bajos en 91 años. Esta situación obligó a la nación a recurrir a otras fuentes de energía, como la termoeléctrica, que solo en julio de 2021 produjo 13.2 \% de la energía total brasileña, incrementando los costos a los consumidores. En el caso de la agricultura, este sector representa $25 \%$ del producto interno bruto (PIB), y se concentra en la producción de cultivos muy intensivos hídricamente, como son la soya, el café, la caña de azúcar, así como en la ganadería. La agricultura de riego representa el $13 \%$ de la superficie cultivada (ANA, 2021) y el 68 \% del consumo anual de agua, con alrededor de 68.4 billones de litros por día (ANA, 2019). Sin embargo, el agua no está disponible de manera uniforme a lo largo y ancho del país, ni a lo largo del año.

De esta forma, una lección de lo acontecido en Brasil durante 2021 es que las crisis hídricas afectan incluso a aquellos países con grandes reservas de agua y estas se deben principalmente a la interacción de la sequía con las actividades humanas. Sin embargo, es necesario reconocer que las condiciones de sequía por sí solas no explican la recurrencia de las crisis hídrica y económica en todo el mundo. Existe una evidente falta de reconocimiento del agua como recurso natural invaluable (porque ihace posible la vida!), lo que se traduce en una larga historia de manejo inadecuado que no habilita su cuidado y sustentabilidad.

La paradoja del valor del agua identificada por Adam Smith hace cientos de años sigue sin resolverse. Continuamos como sociedad dando más valor económico a los diamantes que al agua, a pesar de que estos son infinitamente menos valiosos para la economía y el sustento de la vida. El sistema económico es incapaz de expresar el valor del agua a través de un precio, y cada vez más en el debate público comenzamos a apreciar otras dimensiones existentes para el valor del agua (cultural, recreativo, religioso) lo que hace evidente algo que está en la intuición de todos los pueblos y comunidades del mundo: el agua vale más que el dinero. Por esta razón, no hay una nación en el planeta que equilibre el abastecimiento y la demanda del agua a través de precios en el mercado.

Como sociedad, tenemos un serio problema al dar por sentado, como usuarios del agua, su disponibilidad y calidad. Por ejemplo, algunas de las industrias con las huellas hídricas más grandes siguen sin considerar la falta de agua como un riesgo para sus operaciones. Mientras tanto, desde 2020 , el Foro Económico Mundial incluyó la crisis hídrica como uno de los riesgos globales más importantes por su impacto en la producción de alimentos, la salud humana, los conflictos sociales y los ecosistemas 
(WEF,2020). Pero no necesitamos mirar al futuro para evaluar estos riesgos y sus impactos, ya en el año 2021 hemos sido testigos del tamaño de los impactos sociales y económicos derivados de la crisis hídrica, lo que nos impone la necesidad de evolucionar y trascender la manera en que pensamos al agua.

La crisis que hoy vivimos abre la puerta a una oportunidad para esta evolución. En todo el mundo, una de las fallas identificadas como el origen de grandes conflictos es la consideración de la disponibilidad de agua estática en el tiempo (p. ej. a lo largo del año). Los cambios en el clima y la presencia de sequías cada vez más intensas y severas hacen evidente la falta de compresión sobre cómo responde la disponibilidad de agua a diferentes procesos físicos que se dan en el territorio (p. ej. deforestación, cambios en el uso del suelo, la extracción inmoderada de agua). Por esta razón, es imperativo mirar al agua como un bien común de interés público de todos los mexicanos. La transformación en la forma en que la pensamos y tomamos decisiones, requiere de expertos que respondan a los intereses de la nación y que actúen bajo principios éticos y de sustentabilidad.

Estos principios trascienden también hacia la atención de la crisis ambiental, que ha centrado su atención en la generación de promesas de inversionistas sobre acciones climáticas y compromisos para reducir sus emisiones de carbono, pero que fallan, y por mucho, en reconocer que el cambio climático está ahogando o secando sus activos con exceso y falta de agua. La transformación del sector hídrico nacional requiere también de una evolución en la forma en la que se hacen las inversiones privadas. Las crisis hídricas del presente son una señal inequívoca para cambiar nuestra relación con este elemento vital. El agua segura y los ecosistemas saludables son mucho más valiosos que los diamantes y, contrario a estas piedras preciosas, pueden no ser para siempre, si es que no cambiamos la manera en la que tomamos las decisiones y dirigimos los flujos financieros, tanto hacia el cuidado de la vida como hacia la sustentabilidad hídrica.

Por último, es importante reconocer que, en todo el mundo, esta transformación ya se está dando de forma empírica, pues existen casos que documentan una nueva manera en que las empresas trasnacionales definen dónde y cuándo realizar sus inversiones, considerando un lente de sustentabilidad hídrica. Este paradigma obliga a las compañías a revisar la forma en que los requerimientos de agua durante su operación alteran el ciclo hidrológico local o compiten por el vital líquido con otros usuarios en acuíferos y cuencas con alto estrés hídrico. Un conflicto social o una sequía severa pueden ulteriormente poner en riesgo su inversión. Es el caso de la empresa fabricante de chips para computadoras Intel, que para definir el lugar de su nueva fábrica de micro-procesadores en Nuevo México (una región caracterizada por un alto estrés hídrico) requirió de un acuerdo con el organismo operador de Albuquerque para instalarse. Este acuerdo estableció que la empresa se haría cargo del costo de la infraestructura hidráulica necesaria para satisfacer la demanda hídrica de su nueva planta (entre 4,000 y 10,000 m³ / día), lo que implica una inversión de aproximadamente 32 millones de dólares (AP News, 2022). De igual manera, el 6 de enero pasado, el consorcio cervecero de Constellation Brands anunció una inversión de 5,000 millones de dólares para construir su nueva planta cervecera en Veracruz, México, una región de alta disponibilidad de agua, tras el rechazo social mayoritario a la instalación de su planta en la ciudad de Mexicali, Baja California, zona caracterizada por un muy alto estrés hídrico (El Financiero, 2022). Estos dos ejemplos, Intel y Constellation Brands, nos demuestran que es posible construir acuerdos entre el sector público y privado que fomenten la inversión y crecimiento económico, al mismo tiempo que se cuida al agua y se considera la sustentabilidad hídrica de cuencas y acuíferos. 
Autor: Adrián Pedrozo Acuña.

DOI: doi.org/10.24850/b-imta-perspectivas-2022-01

\section{Referencias}

ANA, 2019. National Water and Basic Sanitation Agency. Manual of Consumptive Uses of Water in Brazil. ANA, 2020. National Water and Basic Sanitation Agency. Report on the Situation of Water Resources in Brazil 2020.

ANA, 2021, National Water and Basic Sanitation Agency. Atlas Irrigation 2021: Water Use in Irrigated Agriculture 2nd ed.

AP News, 2022, Computer chip maker to pay $\$ 32 \mathrm{M}$ for water pipeline, https://apnews.com/article/technology-business-albuquerque-utilities-water-utilities-

1f969c6143dca658d988e5ff2d9fcf14

El Financiero, 2022. Constellation Brands anuncia inversión por 5 mil mdd para su planta de cerveza en Veracruz, https://www.elfinanciero.com.mx/empresas/2022/01/06/constellation-brands-anunciainversion-por-5-mil-mdd-para-su-planta-de-cerveza-en-veracruz/

Geritana, A. 2016. Extreme water deficit in Brazil detected from space. Journal of Hydrometeorology. Pages 591-599. DOI: https://doi.org/10.1175/JHM-D-15-0096.1 